\title{
Electrophysiological and Behavioral Evaluation of Auditory Processing in Adults with Dysphonia
}

\author{
Ana Cláudia Mondini Ribeiro Bez ${ }^{1}$ Cyntia Barbosa Laureano Luiz ${ }^{2}$ Sabrina Mazzer Paes ${ }^{10}$ \\ Renata Rangel Azevedo ${ }^{10}$ Daniela Gil ${ }^{2 \odot}$ \\ ${ }^{1}$ Department of Speech Therapy, Universidade Federal de São Paulo, \\ São Paulo, SP, Brazil \\ 2 Department of Speech Therapy, Escola Paulista de Medicina da \\ Universidade Federal de São Paulo, São Paulo, SP, Brazil \\ Address for correspondence Ana Cláudia Mondini Ribeiro Bez, \\ Fonoaudiologia, Universidade Federal de São Paulo, Rua Botucatu, nr. \\ 802, Vila Clementino, São Paulo, SP, 04023-062, Brazil \\ (e-mail: anamondinifono@gmail.com).
}

Int Arch Otorhinolaryngol 2021;25(3):e349-e354.

\begin{abstract}
Keywords

- auditory evoked potential

- hearing

- auditory perception

- dysphonia

- voice

Introduction Dysphonia is an oral communication disorder. The voice and hearing are interrelated aspects. Hearing is an important sensory input for monitoring the vocal pattern. The relation between hearing abilities and dysphonia represents a contribution both in scientific and in clinical terms, especially in cases in which satisfactory results are not achieved in the therapeutic process.

Objective To characterize long-latency auditory evoked potential (P300) with tonal and complex stimuli, and to make a behavioral evaluation of auditory processing in adults with behavioral dysphonia.

Method The sample used for the present study consisted of 20 subjects from both genders with ages ranging from 18 and 58, who were diagnosed with behavioral dysphonia. The evaluations occurred in a single 2-hour session, in which the procedures of clinical history, pure tone and speech audiometries, acoustic immittance measures, and behavioral and electrophysiological evaluations of auditory processing were performed.

Results The descriptive measures of P3 latency elicited by tonal and complex stimuli showed similar results for the right and left ears, without statistically significant differences. In the qualitative analysis, the results observed were within the normality patterns for the P3 component for both tonal and complex stimuli. As for the behavioral evaluation of auditory processing, abnormal results were observed in $100 \%$ of the sample. Abnormalities were found in the auditory skills of ordering and temporal resolution and figure-background obtained from the duration pattern, random gap detection, and dichotic tests (syllables and words), respectively.

Conclusion The evaluated patients presented central auditory processing disorder, evidenced by behavioral assessment.
\end{abstract}

received

August 26, 2019

accepted

March 10, 2020

published online

September 8, 2020
DOI https://doi.org/ 10.1055/s-0040-1710303. ISSN 1809-9777.

\footnotetext{
(c) 2020. Fundação Otorrinolaringologia. All rights reserved.

This is an open access article published by Thieme under the terms of the Creative Commons Attribution-NonDerivative-NonCommercial-License, permitting copying and reproduction so long as the original work is given appropriate credit. Contents may not be used for commercial purposes, or adapted, remixed, transformed or built upon. (https://creativecommons.org/ licenses/by-nc-nd/4.0/) Thieme Revinter Publicações Ltda., Rua do Matoso 170, Rio de Janeiro, RJ, CEP 20270-135, Brazil
} 


\section{Introduction}

Voice and hearing are interrelated aspects. This interrelationship has aroused the interest of scholars to investigate the peripheral and central auditory systems of dysphonic individuals, since many authors have already proven how crucial is the integrity of the auditory system for the development of vocal behavior and the maintenance of vocal quality. ${ }^{1-6}$

In addition, individuals with behavioral dysphonia invariably undergo speech therapy to establish new vocal patterns. This process, in turn, involves not only the regular performance of vocal exercises, but also auditory monitoring at the time of performing these exercises, and poor auditory feedback may be among the reasons for a therapeutic failure.

To establish the full knowledge of the integrity of an individual's auditory system with greater diagnostic accuracy, a thorough auditory assessment, which involves objective and behavioral methods, is required.

The objective methods are the auditory evoked potentials (AEPs), which assess the neuroelectric activity of the auditory pathway from the auditory nerve to the cortex in response to an acoustic stimulus, such as the long-latency auditory evoked potential (P300) cognitive potential. ${ }^{7}$ Long-latency auditory evoked potential is generated by a complex neural network, involving the cortical and subcortical areas, besides connections between the brainstem and reticular formation. It is considered a cognitive potential since it depends on the patient's attention and discriminating ability. ${ }^{8,9}$

The behavioral methods of hearing tests, on the other hand, consist of assessment of the central auditory processing (CAP), which refers to how the individual interprets the information received through hearing. Central auditory processing disorder (CAPD) can be identified by a battery of behavioral tests, that is, dependent on the patient's response and assessment of their different auditory skills.

A literature search on hearing and voice showed mostly studies involving only behavioral auditory measurements in patients with dysphonia, and there were a few studies that used and correlated objective and behavioral methods in the same sample.

Thus, the present study aims at characterizing the P300, with complex and tonal stimuli, and the behavioral assessment of central auditory processing in adults with behavioral dysphonia.

\section{Methods}

The current research was performed in the Universidade Federal de São Paulo (UNIFESP). The study was conducted after the approval of the committee of ethics in research in human beings of the Universidade Federal de São Paulo (UNIFESP) under the number CAAE 37353314.0.0000.5505.

All subjects invited to participate were advised of their free and spontaneous participation. After the acceptance, all participants were instructed on the procedures to be performed and signed the term of free and informed consent (TFIC) authorizing their voluntary participation.
The sample consisted of 20 subjects, 14 women and 6 men, aged between 18 and 59 years, who had ENT diagnosis of behavioral dysphonia. The average age was 36.25 years, with the minimum age being 18 and the maximum age 58 . All participants were recruited from the waiting list for speech therapy at a public voice clinic.

The inclusion criteria for this study were: normal auditory thresholds (up to $25 \mathrm{~dB} \mathrm{HL})^{10}$; word recognition score $\mathrm{t}$ greater than $92 \%$ of correct responses ${ }^{11}$; type A tympanometric curves bilaterally ${ }^{12}$; presence of contralateral acoustic reflexes at adequate levels ${ }^{13}$; Brazilian Portuguese as the spoken language; to be literate; and to have the diagnosis of behavioral dysphonia.

The exclusion criterion of the sample was: diagnosis of presbylarynx obtained through otorhinolaryngological evaluation and previously diagnosed cognitive or neurological alterations. In addition, individuals that, for some reason, did not participate in all stages of the study would be excluded from the sample.

The participants were submitted to procedures including clinical history and electrophysiological and behavioral evaluation of auditory processing as described below.

While obtaining the clinical history, the individuals answered a speech-language questionnaire concerning clinical aspects related to the voice and hearing.

Electrophysiological evaluation was performed using the Smart EP equipment (Intelligent Hearing Systems, Miami, FL, USA). The investigation of auditory evoked potentials was obtained in an acoustic and electrically treated room. The subjects were accommodated in a reclining and comfortable armchair and instructed to remain still, so that myogenic artifacts were avoided. Before the beginning of the examinations, the subjects' skin was prepared with an abrasive paste, and the electrodes, fixed by adhesive tape and arranged as follows: active electrode (position CZ-vertex), reference electrodes (positions $\mathrm{A} 1$ and $\mathrm{A} 2$-lobes of the left and right ears), and ground electrode (located on the forehead), according to the system 10 to 20 . The impedance of the electrodes was measured to be below $5 \mathrm{k} \Omega$, and the difference between each electrode was at most $2 \mathrm{k} \Omega$.

Long-latency auditory evoked potential was obtained with tonal and complex stimuli. The tone stimuli were tone bursts, presented in the frequencies of $1,000 \mathrm{~Hz}$ (frequent stimulus) and $2,000 \mathrm{~Hz}$ (rare stimulus). As for the complex stimuli, the "ba" and "da" syllables were used, the "ba" for the frequent stimulus, and the "da" for the rare stimulus.

As test protocol, 300 stimuli were presented, either tonal or complex, in a proportion of $80 \%$ for the frequent and $20 \%$ for the rare, characterizing the odd-ball paradigm. The polarity used was alternated, at a rate of $1.1 / \mathrm{s}$, filters 1 to $30 \mathrm{~Hz}$, a 600 ms window, and the presentation level was $70 \mathrm{~dB}$ HL.

All participants were initially trained to discriminate between frequent and rare stimuli. After understanding that, the subjects were instructed to focus on the rare stimulus and count the number of times it appeared, and finally to report the total number of rare stimuli at the end of the test. 
This study examined the P3 component, considering the resulting register obtained by the subtraction of the rare stimuli waves from the frequent ones.

Finally, the behavioral evaluation of auditory processing ${ }^{14}$ included the tests: sound localization test, memory for verbal and non-verbal sounds in sequence, alternate disyllable dichotic test (SSW), dichotic consonant-vowel test (DCVT), duration pattern test (DPT), and random gap detection test (RGDT).

The sound localization test (SLT) was performed with a high-frequency instrumental sound (rattle) presented in the directions ahead, above, behind, to the right, and to the left, with the individual's head as reference. The subject remained with his/her eyes closed and was instructed to indicate the direction of the sound source.

For the verbal sequential memory test (VSMT), the syllables pa, ta, ca, and fa were presented in three different arrangements, and the subject was instructed to repeat the sequence presented without visual clue.

The non-verbal sequential memory test (NVSMT) was performed with the sound of four instruments presented in different sequences and without visual clue. The participant was instructed to point the instruments in the sequence in which they were presented.

The other behavioral tests of the central auditory processing test battery, SSW, DCVT, DPT, RGDT, were performed in an acoustic booth. The tests were recorded on a CD connected to a two-channel audiometer and presented via supra-aural TDH-39 headphones. The patient was asked to perform tasks such as: repeating words and naming sounds, according to the specificities of the applied test.

The alternate disyllable dichotic test was performed at $50 \mathrm{~dB}$ SL. The stimuli, disyllables of low predictability, were presented partially superimposed two to two, two in each ear, alternating the competitiveness condition and the ear that started the test. The participant was asked to repeat the stimuli heard in the same sequence in which they were presented.

The DCVT was also performed at $50 \mathrm{~dB}$ SL and consists of the simultaneous presentation of pairs of different syllables (ba, pa, ca, ga, da and ta). The participant was instructed to choose and repeat only one syllable of the presented pair.

The DPT, which was performed at $50 \mathrm{~dB}$ SL with binaural stimulation, is composed of three pure tones with different durations, long (L) (500 ms) and short (S) (250 ms). These were presented in a given order in binaural condition (dichotic test). The individual was asked to name the sequence presented; for example, if he listened to LLS, he/she should answer long-long-short.

Finally, the RGDT was presented at $40 \mathrm{~dB}$ SL, involving clicks with varied interstimulus time intervals. The test consists of a random variation in the intervals of 0 to $40 \mathrm{~ms}$ at the frequencies of $500 \mathrm{~Hz}, 1,000 \mathrm{~Hz}, 2,000 \mathrm{~Hz}$, and $4,000 \mathrm{~Hz}$. The subjects were instructed to listen to the stimulus and to report whether they had noticed one or two tones, and the threshold of gap detection in the frequencies of $500 \mathrm{~Hz}, 1,000 \mathrm{~Hz}, 2,000 \mathrm{~Hz}$, and $4,000 \mathrm{~Hz}$ was defined by the shortest time interval at which the patient is able to identify two sounds. After obtaining the thresholds in each of the frequencies, their values were added and divided by four. In this way, the average value for each patient's responses was obtained.

In the analysis of P300 elicited by tonal stimuli, the reference values proposed by McPherson ${ }^{9}$ were used. For the analysis of the complex stimuli, the Agostinho-Pesse and Alvarenga ${ }^{15}$ proposal of analysis was used.

In the evaluation of central auditory processing, the normality criteria from a previous study performed in Brazil ${ }^{14}$ were used.

For the statistical analyses, the complete descriptive measurements of the quantitative variables were initially grouped, and the average, median, standard deviation, coefficient of variation, quartiles, minimum and maximum values, and confidence intervals were defined.

To characterize the relative frequency distribution (percentages) of the P300 complex stimuli, tone burst P300, and SSW, the two-proportion equality test was used.

To measure the correlation index between the P300 elicited by complex stimulus and the P300 elicited by tone burst stimulus, Spearman correlation was used.

The results with statistical significance were highlighted in red or signaled with the asterisk symbol $\left({ }^{*}\right)$, while the results with a tendency to significance were highlighted in blue or signaled with the number sign (\#). The confidence intervals were constructed with $95 \%$ statistical confidence, and the significance level of 0.05 (5\%) was established.

\section{Results}

- Table 1 shows the results of the descriptive analysis of the P3 component elicited by tonal and complex stimuli, respectively.

- Table 2 shows the results of the qualitative analysis of the P3 component elicited by tonal and complex stimuli, respectively.

Table 1 Descriptive analysis of the P3 component elicited by tonal and complex stimuli

\begin{tabular}{|l|l|l|l|l|l|l|l|l|l|l|l|}
\hline \multicolumn{2}{|l|}{ Descriptive } & Average & Median & Standard deviation & CV & Q1 & Q3 & Min & Max & N & Cl \\
\hline P300 TB latency & RE & 307.6 & 314.0 & 19.9 & $6 \%$ & 290.8 & 320.3 & 266.0 & 336.0 & 20 & 8.7 \\
\cline { 2 - 11 } & LE & 311.0 & 307.5 & 30.8 & $10 \%$ & 284.5 & 333.3 & 268.0 & 371.0 & 20 & 13.5 \\
\hline P300 complex latency & RE & 301.8 & 311.5 & 30.3 & $10 \%$ & 282.3 & 322.5 & 252.0 & 350.0 & 20 & 13.3 \\
\cline { 2 - 11 } & LE & 293.5 & 295.5 & 26.2 & $9 \%$ & 271.3 & 304.0 & 259.0 & 355.0 & 20 & 11.5 \\
\hline
\end{tabular}

Abbreviations: $\mathrm{Cl}$, confidence interval; LE, left ear; RE, right ear; TB, tone burst. 
352 Electrophysiological and Behavioral Evaluation of Auditory Processing Bez et al.

Table 2 Distribution of normal and altered results for P300 latency with tonal and complex stimuli

\begin{tabular}{|l|l|l|l|l|l|}
\hline \multirow{2}{*}{ P300 } & \multicolumn{2}{|l|}{ Altered } & \multicolumn{2}{l|}{ Normal } & \multirow{2}{*}{$p$ Value } \\
\cline { 2 - 5 } & $\mathrm{N}$ & $\%$ & $\mathrm{~N}$ & $\%$ & \\
\hline TB & 0 & $0 \%$ & 20 & $100 \%$ & $<0.001$ \\
\hline Complex & 0 & $0 \%$ & 20 & $100 \%$ & $<0.001$ \\
\hline
\end{tabular}

Abbreviations: P300, long-latency auditory evoked potential; TB, tone burst.

-Table 3 presents the performance of the participants in the behavioral tests of the CAP in percentage of correct answers.

Sound localization tests, VSMT, and NVSMT showed results within normal limits.

The average number of correct answers obtained in the DCVT showed a higher number of right ear hits; however, the number of errors was higher than the accepted.
The altered average was also found in the Duration Pattern Test (DPT) and in the RGDT.

As for the SSW test, the dysphonics patients presented altered performance only for the left ear, while the average values for the right ear were within normal range.

To obtain the correlation between the electrophysiological and behavioral evaluation, the central auditory processing behavioral tests SSW, DCVT, DPT, and RGDT were correlated with the P3 component (-Tables 4 and 5).

It was found that for P300 elicited by tonal stimuli (-Table 4), there was a significant correlation between the latency and the DPT, demonstrating that the higher the P3 latency, the worse the performance in the DPT. As for the amplitude, the correlation indicated that the greater the amplitude of $\mathrm{P} 3$, the greater the percentage of correct answers in the DPT.

For P300 elicited with complex stimuli (-Table 5), no significant correlations with behavioral evaluation were found.

Table 3 Descriptive measures of the percentage of correct answers for sound localization, verbal and non-verbal sequential memory, vowel-consonant, duration pattern, random gap detection, and staggered spondaic word tests

\begin{tabular}{|l|l|l|l|l|l|l|l|l|l|l|l|}
\hline Descriptive & & Average & Median & Standard deviation & CV & Q1 & Q3 & Min & Max & N & IC \\
\hline SLT & & $79.0 \%$ & $80 \%$ & $20.0 \%$ & $25 \%$ & $60 \%$ & $100 \%$ & $40 \%$ & $100 \%$ & 20 & $8.8 \%$ \\
\hline VSMT & 4 syllables & $81.6 \%$ & $100 \%$ & $22.9 \%$ & $28 \%$ & $67 \%$ & $100 \%$ & $33 \%$ & $100 \%$ & 20 & $10.0 \%$ \\
\hline NVSMT & 4 Sounds & $86.6 \%$ & $100 \%$ & $20.0 \%$ & $23 \%$ & $67 \%$ & $100 \%$ & $33 \%$ & $100 \%$ & 20 & $8.8 \%$ \\
\hline DCVT & RE & 10.15 & 10.0 & 2.94 & $29 \%$ & 8.5 & 12.0 & 5.0 & 16.0 & 20 & 1.29 \\
\hline & LE & 6.60 & 6.0 & 3.25 & $49 \%$ & 5.0 & 8.5 & 0.0 & 13.0 & 20 & 1.42 \\
\hline & Mistakes & 7.25 & 8.0 & 2.88 & $40 \%$ & 4.8 & 9.0 & 3.0 & 13.0 & 20 & 1.26 \\
\hline DPT & & $52.5 \%$ & $53 \%$ & $22.1 \%$ & $42 \%$ & $40 \%$ & $63 \%$ & $7 \%$ & $100 \%$ & 20 & $9.7 \%$ \\
\hline RGDT & & 19.99 & 19.6 & 12.00 & $60 \%$ & 10.6 & 28.8 & 2.0 & 40.0 & 20 & 5.26 \\
\hline SSW & RE & $92.9 \%$ & $94 \%$ & $6.2 \%$ & $7 \%$ & $90 \%$ & $98 \%$ & $75 \%$ & $100 \%$ & 20 & $2.7 \%$ \\
\hline & LE & $87.9 \%$ & $90 \%$ & $9.3 \%$ & $11 \%$ & $83 \%$ & $95 \%$ & $68 \%$ & $100 \%$ & 20 & $4.1 \%$ \\
\hline
\end{tabular}

Abbreviations: DCVT, dichotic consonant-vowel test; DPT, duration pattern test; NVSMT, non-verbal sequential memory test; RGDT, random gap detection test; SLT, sound localization test; SSW, staggered spondaic word; VSMT, verbal sequential memory test.

Table 4 Correlation between P300 elicited by tonal stimulation and central auditory processing tests

\begin{tabular}{|c|c|c|c|c|c|c|c|c|c|}
\hline \multicolumn{3}{|l|}{ P300 TB } & \multicolumn{2}{|l|}{ SSW } & \multicolumn{3}{|l|}{ DCVT } & \multirow[t]{2}{*}{ DPT } & \multirow[t]{2}{*}{ RGDT } \\
\hline & & & $\mathrm{RE}$ & $\mathrm{LE}$ & RE & LE & Mistakes & & \\
\hline \multirow[t]{4}{*}{ P3 latency } & \multirow[t]{2}{*}{ RE } & Corr (r) & $-14.3 \%$ & $8.1 \%$ & $-20.7 \%$ & $24.2 \%$ & $-4.2 \%$ & $1.3 \%$ & $-13.1 \%$ \\
\hline & & $p$-Value & 0.547 & 0.735 & 0.380 & 0.303 & 0.861 & 0.957 & 0.583 \\
\hline & \multirow[t]{2}{*}{ LE } & Corr $(r)$ & $-12.5 \%$ & $-6.9 \%$ & $-15.1 \%$ & $7.2 \%$ & $3.3 \%$ & $-51.9 \%$ & $29.5 \%$ \\
\hline & & $p$-Value & 0.601 & 0.774 & 0.525 & 0.764 & 0.889 & 0.019 & 0.206 \\
\hline \multirow[t]{4}{*}{ P3 amplitude } & \multirow[t]{2}{*}{ RE } & Corr (r) & $4.3 \%$ & $-28.6 \%$ & $13.4 \%$ & $-19.2 \%$ & $7.6 \%$ & $50.2 \%$ & $-16.6 \%$ \\
\hline & & $p$-Value & 0.858 & 0.221 & 0.573 & 0.417 & 0.750 & 0.024 & 0.486 \\
\hline & \multirow[t]{2}{*}{$\mathrm{LE}$} & Corr (r) & $16.1 \%$ & $2.7 \%$ & $13.0 \%$ & $-4.7 \%$ & $-7.5 \%$ & $46.3 \%$ & $-33.9 \%$ \\
\hline & & $p$-Value & 0.497 & 0.909 & 0.586 & 0.844 & 0.755 & 0.040 & 0.144 \\
\hline
\end{tabular}

Abbreviations: DCVT, dichotic consonant-vowel test; DPT, duration pattern test; LE, left ear; RE, right ear; RGDT, random gap detection test; SSW, staggered spondaic words. 
Table 5 Correlation between P300 elicited by complex stimulation and central auditory processing tests

\begin{tabular}{|c|c|c|c|c|c|c|c|c|c|}
\hline \multicolumn{3}{|l|}{ P300 speech } & \multicolumn{2}{|l|}{ SSW } & \multicolumn{3}{|l|}{ DCVT } & \multirow[t]{2}{*}{ DPT } & \multirow[t]{2}{*}{ RGDT } \\
\hline & & & RE & LE & RE & LE & Mistakes & & \\
\hline \multirow[t]{4}{*}{ P3 latency } & \multirow[t]{2}{*}{ RE } & Corr (r) & $23.2 \%$ & $42.1 \%$ & $-35.1 \%$ & $35.2 \%$ & $-12.4 \%$ & $8.3 \%$ & $-26.5 \%$ \\
\hline & & $p$-Value & 0.324 & 0.065 & 0.129 & 0.128 & 0.604 & 0.727 & 0.260 \\
\hline & \multirow[t]{2}{*}{ LE } & Corr (r) & $-12.7 \%$ & $15.6 \%$ & $-17.5 \%$ & $13.4 \%$ & $-0.6 \%$ & $-24.2 \%$ & $-1.8 \%$ \\
\hline & & $p$-Value & 0.595 & 0.511 & 0.461 & 0.574 & 0.978 & 0.304 & 0.940 \\
\hline \multirow[t]{4}{*}{ P3 amplitude } & \multirow[t]{2}{*}{ RE } & Corr (r) & $-12.7 \%$ & $-18.7 \%$ & $3.9 \%$ & $-22.1 \%$ & $31.7 \%$ & $-2.9 \%$ & $-22.0 \%$ \\
\hline & & $p$-Value & 0.593 & 0.429 & 0.869 & 0.349 & 0.173 & 0.904 & 0.352 \\
\hline & \multirow[t]{2}{*}{$\mathrm{LE}$} & Corr (r) & $-19.7 \%$ & $-25.3 \%$ & $-0.3 \%$ & $-21.1 \%$ & $26.8 \%$ & $2.6 \%$ & $-14.1 \%$ \\
\hline & & $p$-Value & 0.405 & 0.282 & 0.989 & 0.372 & 0.253 & 0.914 & 0.554 \\
\hline
\end{tabular}

Abbreviations: Corr, correlation; DCVT, dichotic consonant-vowel test; DPT, duration pattern test; LE, left ear; RE, right ear; RGDT, random gap detection test; SSW, staggered spondaic word test.

\section{Discussion}

Currently, the electrophysiological evaluation, especially involving P300, has been considered an important complement for the behavioral evaluation of auditory processing, since the first one would reveal alterations in the functioning of the auditory pathway and the second one would demonstrate the auditory abilities in which this inadequate functioning would have repercussions.

This study evaluated the hearing system of dysphonic adults by means of electrophysiological and behavioral measures.

The descriptive analysis of the P3 components demonstrated similar average values between the ears with both complex and tonal stimuli ( - Table 1 ). In the qualitative analysis, we observed results within normal range for P300 elicited with complex and tonal stimuli (-Table 2).

Luiz $(2018)^{16}$ also performed the electrophysiological evaluation in individuals diagnosed with dysphonia. Her findings corroborate this study, with the P3 values remaining within normal range. In a population composed of normal listeners, these data were also similar. ${ }^{17,18}$

It is noteworthy that there is a wide range of normality for P300 latency values, which may justify the normality found not only in adults with dysphonia.

In the behavioral evaluation (-Table 3 ), changes were observed in figure-background auditory abilities for words and syllables, in the analysis of the duration of sounds and in temporal resolution aspects.

In the present study, the changes observed in the SSW test and in the DCVT reiterate the difficulties in the perception of the speech in a situation of competitive in this population. Communication in adverse environments occurs at most times during communication. Difficulties in achieving effective communication may lead to vocal abuse, resulting in the use of higher voice intensity. This frequent vocal abuse, in turn, can lead to vocal injuries and, consequently,dysphonia.
As for the temporal tests, whose auditory stimuli were non-verbal, the average performance was altered for both DPT and RGDT.

The studied population showed greater difficulty in temporal patterns, which are considered the basis of auditory processing mainly in what concerns the perception of speech, since many characteristics of speech information are somehow influenced by time. ${ }^{19}$

These findings are in agreement with other studies, ${ }^{1,6}$ which also revealed difficulties in temporal processing for the population with voice alteration.

Other studies involving vocal production and auditory perception described the importance of auditory aspects in voice evaluation and rehabilitation, stating that patients undergoing voice therapy without an adequate auditory perception would account for therapeutic failure. ${ }^{1,20}$

In the study of correlations between electrophysiological and behavioral measures, there was a negative correlation for latency, and a positive correlaton for amplitude, both for P300 elicited by tonal stimuli in relation to behavioral DPT (-Table 4).

The higher the P3 latency, the worse the performance in the DPT. There is a direct relation between P300 latency and information processing speed. Increase of the P300 latency is observed with the more complex processing tasks and with short-term memory demands. ${ }^{21}$

The worst performance in the DPT demonstrates that the temporal processing ability can be considered a complex task for subjects in the present study, resulting in increased P300 latency with tonal stimulus.

As for the amplitude, the correlation indicated that the greater the amplitude of $\mathrm{P} 3$, the greater the percentage of correct answers in the DPT. The amplitude is related to the event or task involved in the response and to the amount of neural sources that the attention system needs for the execution of the task. ${ }^{22}$ The P300 amplitude is greater for easier tasks and decreases as the task becomes more difficult. $^{9}$ The electrophysiological evaluation did not coincide with the performance in the DPT. 
However, for the PEALL elicited by complex stimuli, no statistically significant correlations were found ( $\mathbf{- T a b l e ~} \mathbf{5}$ ). It was not possible to observe the relationship between the complex-stimulated P300 and the auditory processing behavioral tests selected for the current study.

The present study confirmed the difficulties of auditory processing in dysphonic subjects, especially in terms of behavioral evaluation. Therefore, it is recommended to evaluate the auditory processing in these individuals to establish the therapeutic objectives more precisely. In the case of altered auditory processing by auditory processing tests, the stimulation of the auditory abilities, such as in the auditory training, should be considered to maximize the benefits of the auditory perceptive exercises.

More studies are necessary in order to expand the correlation between voice and auditory processing disorders in the dysphonic population, with comparative pre and postintervention measures, as well as studies with longitudinal follow-up.

\section{Conclusions}

The dysphonic patients evaluated presented alterations in the behavioral evaluation of the auditory processing, involving auditory figure-background and temporal processing abilities.

\section{Conflict of Interests}

The authors have no conflicts of interest to declare.

\section{References}

1 Buosi MMB, Ferreira LP, Momensohn-Santos TM. Percepção auditiva de professores disfônicos. ACR 2013;18(02):101-108

2 Selleck MA, Sataloff RT. The impact of the auditory system on phonation: a review. J Voice 2014;28(06):688-693

3 Behlau MS, Madazio G, Feijó D, Azevedo R, Gielow I, Reher MI. Aperfeiçoamento vocal e tratamento fonoaudiológico das disfonias. In: Voz: o livro do especialista Vol. II. Rio de Janeiro: Revinter; 2010: 409-565

4 Cavadas M, Pereira LD, Behlau M. Disfonia infantil e processamento auditivo central. In: Valle MGM. Voz: Diversos Enfoques em Fonoaudiologia. Rio de Janeiro: Revinter; 2002
5 Sanches AB. Processamento auditivo central em crianças com disfonia: avaliação comportamental e eletrofisiológica [dissertação]. São Paulo: Universidade Estadual de Campinas; 2016

6 Ramos JS, Feniman MR, Gielow I, Silverio KCA. Correlation between Voice and Auditory Processing. J Voice 2018;32(06):771. e25-771.e36

7 Matas CG, Magliaro CL. Aplicações Clínicas dos Potenciais Evocados Auditivos de Curta e Média Latência. In: Marchesan IQ, Justino H, Tomé MC. Tratado das Especialidades em Fonoaudiologia. 1를 Ed. São Paulo: Guanabara Koogan; 2014:893-905

8 Matas CG. Audiometria de tronco cerebral. In: Carvallo RMM. Fonoaudiologia: informação para a formação - procedimento em Audiologia. São Paulo: Guanabara Koogan; 2003:43-56

9 McPherson DL. Late potentials of the auditory system (evoked potentials). San Diego: Singular Publishing Group, Inc.; 1996

10 Davis H, Silverman SR. Hearing and Deafness. $3^{\text {rd }}$. ed. New York: Holt, Rinehart, and Winston; 1970

11 Jerger J, Speaks C, Trammell JL. A new approach to speech audiometry. J Speech Hear Disord 1968;33(04):318-328

12 Jerger J. Clinical experience with impedance audiometry. Arch Otolaryngol 1970;92(04):311-324

13 Jerger S, Jerger J. Alterações auditivas: um manual para avaliação clínica. São Paulo: Atheneu; 1989

14 Pereira LD, Schochat E. Processamento Auditivo Central: manual de avaliação. São Paulo: Lovise; 1997

15 Agostinho-Pesse RS, Alvarenga KF. Potencial Evocado Auditivo de longa latência para estímulo de fala apresentado com diferentes transdutores em crianças ouvintes. Rev CEFAC 2014;16(01):13-22

16 Luiz CBL. Avaliação eletrofisiológica e comportamental da audição em pacientes disfônicos pré e pós terapia fonoaudiológica. Tese (doutorado em ciências) - Universidade Federal de São PauloSão Paulo2018:73

17 Oppitz SJ, Didoné DD, Silva DD et al. Long-latency auditory evoked potentials with verbal and nonverbal stimuli Braz J. Otorhinolaryngology 2015;81(06):647-653

18 Massa CGP, Rabelo CM, Moreira RR, Matas CG, Schochat E, Samelli AG. P300 in workers exposed to occupational noise. Rev Bras Otorrinolaringol (Engl Ed) 2012;78(06):107-112

19 Samelli AG, Schochat E. The gaps-in-noise test: gap detection thresholds in normal-hearing young adults. Int J Audiol 2008;47 (05):238-245

20 Faria DM, Paoliello KBG, Gielow I. Disfonia e processamento auditivo central. In: Fundamentos e atualidades em voz clínica. São Paulo: Revinter; 2019:181-191

21 Hall JW. Handbook of auditory evoked responses. Boston: Allyn and Bacon; 2006

22 Picton TW. The P300 wave of the human event-related potential. J Clin Neurophysiol 1992;9(04):456-479 